\title{
Induction of Male Sterility: A Boon for Plant Breeding
}

\author{
Kanti Meena ${ }^{1,2}$ and K.B.R.S. Visarada ${ }^{2 *}$ \\ ${ }^{1}$ ICAR-Central Research Institute for Jute and Allied Fibres (CRIJAF), \\ Barrackpore, Kolkata, India \\ ${ }^{2}$ ICAR-Indian Institute for Millets (IIMR), Rajendranagar, Hyderabad, India \\ *Corresponding author
}

\section{A B S T R A C T}

\begin{tabular}{l} 
Ke y w o r d s \\
Antibiotics, \\
Chemical \\
hybridizing agent, \\
Hybrid seed, Male \\
sterility, \\
Mitochondria, \\
Pollen grains \\
\hline $\begin{array}{l}\text { Article Info } \\
\text { Accepted: } \\
\text { 10 January } 2021 \\
\text { Available Online: } \\
\text { 10 February } 2021\end{array}$ \\
\hline
\end{tabular}

\section{Introduction}

In general, the life cycle of plants consists of two phases, one prolonged vegetative or sporophytic generation and a short sexual or gametophytic generation. During the entire period a seed germinate, differentiate into root and shoot, undergoes vegetative growth and completes its life cycle once the flower is converted into fruit. Male sterility is a common phenomenon seen in higher plant species. Inability of a living organism for sexual reproduction is known as sterility and failure to produce functional pollen is called male sterility. In agriculture, male sterility has been proven as highly beneficial to produce hybrid seeds which are often superior in terms of quality and yield compared to their parents. Plants exhibits diverse forms of male sterility, like absence of normal anthers or reduced anther size, difference in petaloidy, abnormal meiosis which leads to formation of empty, shriveled microspores or normal meiosis, but with abnormal microspore development and failure of anthesis that doesn't allow pollen shed (Kaul, 1988). In all the above cases of 
male sterility, the female gametes are fertile with normal function. Male sterility in plants was first reported within species and speciesspecific hybrids as anther abortion in Verbascum phoeniceum by Koelreuter (1763). These male sterile plants are either selected from natural populations or may be induced artificially through mutagenesis. Anther and pollen development pathway consist of several stages involving formation of stamen, anther, pollen and anther dehiscence at maturity followed by pollen shed. Development of anther and pollen has been well studied in Arabidopsis (Wilson and Zhang, 2009), and many of the key genes involved in this pathway have been identified. During the process, the tapetum plays a central role in supplying nutrients, proteins, lipids and polysaccharides that are associated with pollen-wall formation and release of microspore (Parish and Li, 2010). Thus, most often, tapetal cells are targeted for inducing male sterility, this indicates very crucial role of mitochondria in male organ development.

\section{Hybrid seed production}

It is an important tool for improving the productivity of any crop for which occurrence of male sterility is critical. Crops, where large-scale emasculation is a tedious job, male sterile lines permit hybrid seed production as well as commercial exploitation of heterosis. Presence of genetic male sterility or genetic cytoplasmic male sterility, which are used for commercial purposes are not available in many crops. To enhance the production of hybrid seed at large-scale, to reduce the cost of hybrid seed production for commercial purpose, to minimize huge manpower required for emasculation and crossing and to hasten up the breeding programs, many efforts are made to induce male sterility in plant species. Heterosis, or hybrid vigor, has been shown to increase yield and successfully commercialized in many crops. Different methods such as Cytoplasmic Male Sterility (CMS), Chemical Hybridizing Sterility (CHS) etc are in use that ensure cross-pollination rather than selfing for hybrid production to, are diverse and species specific (Cheng et al., 2007; Longin et al., 2012). In the modern agriculture sector production of hybrid plants plays critical role in terms of increasing the production and in improving the product quality (hybrid vigor). But, hermaphrodite nature of most of the plants is the bottleneck in the cross between two different plants. Due to which fertilization occurs within the plants (self-pollination), so inhibiting selfpollination by any means (genetically, chemically or physically), which can disturb the male organs or the male gametes, facilitating cross pollination of plants and hybrid production in a large- scale is practiced. Thus, development of CMS lines for hybrid seeds is important as it evades selfpollination.

\section{Types of male sterility and its use in plant breeding}

Male sterility in simple terms refers to failure of a plant to produce functional anthers or male gametes. Once the concept and importance of hybrid vigor was realized, this trait was utilized to incorporate into many crop species for crop improvement (Sage, 1976). The term heterosis or hybrid vigor means superiority of progeny to its parents in terms of yield, followed by other traits like biotic or abiotic stresses, its adaptability to different environmental conditions, its vegetation etc based on the type of crop involved. Hybrid vigor is considered for progenies (hybrid) that are developed by crossing two parents in either to incorporate desired traits of one parent into another or for development of new hybrid. Development of hybrids is a challenging task in self-pollinated crops as it requires avoidance of selfpollination, which is conventionally carried 
out by emasculation method. It is a tedious job involving time, manpower and skill. Here male sterile lines come into picture with a leading role that permits hybrid seed production as well as commercial exploitation of heterosis. Male sterility is either phenotypic or genotypic in nature and the genotypic male sterility can be genetic or cytoplasmic.

\section{Cytoplasmic male sterility (CMS)}

Cytoplasmic male sterility is not a common type of male sterility in nature (Vinod, 2005) and arises due to spontaneous mutation in organelle (especially in mitochondrial) involving rearrangements of the mitochondrial genome. Mutations in CMS are due to different recombination events that occur between homologous and nonhomologous genome of the two individuals resulting in new Open Reading Frames (ORFs) (Dufay et al., 2007). The CMS trait is maternally inherited, due to which transfer of the CMS character from the female parent to the progeny plant is carried out and the progenies are completely male sterile. During crossing a CMS plant is used as female partner or recipient, while a fertile plant is used as male partner (pollen donor). The contribution of the male parent is limited mainly to nuclear traits (Laughnan and Gabay-Laughnan, 1983). In CMS system cytoplasm plays critical role for the development of male sterile or fertile lines. So, there are two types of cytoplasm Viz., S type (sterile) and $\mathrm{N}$ type (normal). Such male sterility is stable and can be seen in a large number of crops, however cannot be used were seed is an economic part.

Use of CMS lines for generating hybrids was first employed in maize, thereafter it has been continuously expanded in major food crops like wheat and rice (cereals), onion, carrot, sugar beet, pepper (vegetables), brassicaceae, sunflower, soybean (oilseeds), sorghum, pear millet (millets), legumes etc (Mackenzie, 1988; Singh et al., 2015; Bohra et al., 2016; Kalia et al., 2019). CMS provides an expedient mechanism to produce large populations of male-sterile plants for commercial $F_{1}$ hybrid seed production. Apart from hybrid seed production, CMS system can also be utilized for basic studies. It can be used as a model system to study the interaction between the genetic material of both mitochondria and nucleus, different genes responsible for induction of male sterility (Hanson and Bentolila, 2004) and development of male gametophytes (Fujii et al., 2011). It also helps us to study role of mitochondria in the development of reproductive organs in flowering plants (Hanson and Bentolila, 2004) and to develop seedless citrus varieties (Fang et al., 2016).

\section{Cytoplasmic-genetic male sterility (CGMS)}

Cytoplasmic genetic male sterility (CGMS) is very common and available throughout the plant kingdom (Vinod, 2005). It mainly arises due to the compatible interaction and double mutation in both mitochondrial and nuclear genomes. Here also there are two types of cytoplasm as in case of CMS, however restorers with fertility (Rf) genes are also present. These genes don't express unless they come in contact of S cytoplasm. So, a combination of $\mathrm{S}$ cytoplasm with $\mathrm{rfrf}$ produces only sterile lines, whereas $\mathrm{N}$ cytoplasm with RfRf combined with $\mathrm{S}$ cytoplasm and rfrf leads to fertile lines. The restore genes in CGMS differ from $\mathrm{Rf}$ genes present in genetic male sterility. During this interaction male sterility is induced by mitochondrial genes, whereas nuclear genes restore the male fertility ( $\mathrm{Rf}$ genes) traits. This type of male sterility system was first identified in onion (Jones and Davis, 1944), later it was seen in other crops such as jowar, bajra, maize, cotton, sunflower, rice and 
wheat. It is highly reliable and stable system and can be used in both seed and vegetative propagated crops. The difference between CMS and CGMS is due to their fertility restoration mechanisms. In CMS male fertility is regulated by $\mathrm{N}$ type cytoplasm of the maintainer line, whereas in CGMS, dominant, fertility restoring genes are located in the nucleus of restorer line, leads to fertility restoration. For breeding and CGMS based hybrid seed production involves three different lines as used in CMS system.

\section{Genetics and Mechanism behind CMS}

The sterility factor (S) is present on mitochondrial DNA, whereas the fertility restorer allele (rf) is present on nucleus genome. For breeding and hybrid seed production CMS and CGMS system involves three different lines. A line (sterile) having both recessive allele (rfrf) and (S) factor (Sterile cytoplasm), B line denoted as maintainer of the female line (male sterile) and has fertile $(\mathrm{N})$ cytoplasm with recessive restorer allele in nucleus (rfrf). When an identified A line (male sterile) is crossed with male fertile $\mathrm{B}$ line (maintainer) having recessive ' $r f r f$ ' factor and cytoplasm $(\mathrm{N})$, all the resultant progenies are male sterile (with $\mathrm{S}$ cytoplasm) with same nuclear constitution (rfrf) as both A and B line has recessive allele for fertility restoration. The B line has an ability to make the A line set seed in the progeny, but the plant remains sterile, thus the CMS line is maintained (Figure 1a). If $\mathrm{R}$ line (restorer), which contains dominant allele for fertility restoration (RfRf) is identified for CMS then it can be used for hybrid seed production. This line has the ability to restore the male fertility of the hybrid plants $\left(\mathrm{F}_{1}\right)$. These restorer lines are identified and are used for commercial hybrid seed production. So, when a CMS with S cytoplasm and rfrf is crossed with restorer line having $\mathrm{N}$ cytoplasm and dominant fertility restorer gene (RfRf), thus sterility inducing effect of CMS cytoplasm is reversed and leads to fertile hybrids. For large scale seed production, the progenies are selfed (Figure 1b). In the next phase, if a new genotype is intended to make CMS, then the pollen from the intended line will be used on the identified CMS line. This will constitute male sterile cytoplasm, but nucleus is composed $50 \%$ original and $50 \%$ intended line. Resultant CMS plant will be repeatedly back crossed with the pollen from the intended plant to restore nucleus of the intended line, but the cytoplasm will be male sterile (Figure 1c).

Genetic male sterility arises due to spontaneous variation in male fertility nuclear genes (independent of cytoplasm influence) and follows Mendelian gene inheritance pattern. This is one of the most common forms of male sterility found in many plants (Kaul, 1988) both in monocots and dicots. It is governed by recessive gene (ms), which targets the entire process of male organ development leading to male sterility. It involves an extra- step such as identification and removal of heterozygotes from the group, for hybrid seed production. When male sterile line (msms) is crossed with male fertile parent (MsMs), all $\mathrm{F}_{1}$ progenies are male fertile (Msms) due to the presence of dominant fertility controlling allele (Figure 2). Inheritance of dominant male sterility is suitable for hybrid seed production as it represents $75 \%$ of the population sterile (Figure 3a), whereas inheritance of recessive male sterility represents only $25 \%$ population sterile (Figure $3 b$ ). These sterile lines may be lost if they are not maintained as heterozygotes (Msms), thus they need to be pollinated with either a fertile hetero (Msms) or homozygous (MsMs) maintainer line. But if the expression is controlled by a dominant allele (MsMS) it is difficult to maintain the lines through reproductive means. Utilization of GMS in hybrid seed production involves 
two lines and its use was limited for hybrid seed production due to improper maintenance of male sterile lines. These limitations were overcome with development of Environmental Genetic Male Sterility, (EGMS), which doesn't need any maintainers.

\section{Environmental dependent genetic male sterility}

In this system male sterility and fertility trait are expressed and controlled by specific environment conditions like temperature (low or high), variable light intensity (short or long photoperiod), different soil borne stresses (Kaul, 1988). This system is heritable in nature. Sterility trait is controlled only by single recessive nuclear gene without the involvement of cytoplasm, so there is no need for fertility restorer lines to convert the sterile lines into fertile. Hybrid rice has been successfully developed and applied widely in agriculture based on two-line system using photosensitive genetic male sterility (PGMS) and thermosensitive genetic male sterility (TGMS) lines (Zhou et al., 2012; Chen and Liu, 2014). PGMS was discovered by Shi (1981), where sterility in plant depends upon the length of photoperiods. Male sterile mutant rice lines were induced using either sterile or fertile pollen depending on the changes in temperature (Yang and Wang, 1989). TGMS is controlled by a single recessive nuclear gene (msms), where plant remains sterile or fertile at a particular temperature or photoperiod (Virmani and Ilyas-Ahmed 2001).

\section{Confirmation of type of male sterility generated}

Identification of type of male sterile system induced by any of the above-mentioned method can be carried out by detecting its progeny on crossing with normal or control genotype. In the first case if all the progenies in a row are sterile then the system is cytoplasmic male sterility (CMS). In the second case if some rows are fertile and some rows show both fertile and sterile individuals in 1:1 ratio then the system belong to genetic male sterility (GMS). In the third case if some rows are completely sterile, some rows are completely fertile and some rows containing both sterile and fertile lines in the ration 1: 1 then the male sterility belongs to cytoplasmic genetic male sterility (CGMS).

\section{How male sterility is introduced}

Under traditional breeding, the plant breeders emasculate the anthers by hand to prevent self-pollination for crossing, which is a labour intensive as well as cost expensive procedure, however, with the availability and use of male sterile lines hybrid seeds can be produced easily for research or cultivation. Sterility can be genetic (nuclear) termed as genetic male sterility (GMS) or can be due to cytoplasmic termed as (CMS) due to the genome of mitochondria. These sterile genes can be recessive or dominant. The recessive inheritance of GMS made it difficult to fully utilize its potential, because the resultant progeny is $50 \%$ sterile and $50 \%$ fertile, thus attention of breeders was inclined more towards CMS where $100 \%$ sterility is achieved. CMS is widespread in occurrence in higher plants and is reported in more than three hundred species (Kaul 1988). The majority of CMS are due to wide hybridization, spontaneous mutation, using mutagenic and chemicals hybridizing agents (CHA) as gametocides, using frontier tools of biotechnology such as genetic engineering. Many efforts have been made in this endeavor.

\section{Natural variation}

Nature is a collection for unlimited variations and some of the economically important traits 
has been collected, characterized and exploited in the past in different crops by the researchers. A revolution in seed sector and in hybrid seed programme was seen with the identification of male sterility trait that made us self-sufficient. Generation of genetic variations is a continuous process by the nature, which need to be carefully observed and selected by the researchers in the near future.

\section{Wide hybridization}

Intergeneric hybridization involves cross between two different genera. In this type, crosses may not be successful due to highly diverse nature of the two parents. In such cases, the embryos are rescued by in vitro culture. Resultant hybrid may be sterile due to some abnormalities during meiosis. On the other hand, interspecific hybridization involves cross between species within the genera. It may be either between wild relative with a cultivated parent or within the cultivars, thus development of a new genotype (integration of cultivated nucleus into the cytoplasm of wild species). Breeding populations developed from different intervarietal crosses sometimes generate new genetic variation that may arise due to rare recombination of recessive alleles or transgressive segregation. In many crops like pearl millet, soybean, and cotton, cytoplasmic nuclear male sterility has been derived from recombinant populations in the past (Kaul, 1988). The frequency of such useful recombination is, however, very low.

This is being used as the most common and successful approach for breeding cytoplasmic nuclear male- sterile genotypes in many crop species of cereals, legumes. Wide crosses in development of CMS lines have been reported in oilseed crops. In soybean, Sun et al., (1997) crossed wild-type Chinese Glycine max and wild annual G. Soja and in the progeny the pollen grains showed mitochondria with degraded plastids, puffy inner mitochondrial spaces, undeveloped intine, and absence of starch and lipid reserves. Thus, mentioned degeneration of mitochondria and energy deficiency leads to male sterility (Smith et al., 2002). Similarly, Ding et al., (2002) crossed two cultivated Glycin max cultivars and reported male sterile progenies followed by backcrosses that resulted in CMS, no pollen germination was observed and pollen abortion was recorded at binucleate stage. Wide crosses between Sesamum indicum and $S$. malabaricum revealed male sterile lines due to cytoplasmic differences in the two parents (interaction of the cytoplasm of $S$. malabaricum with the nuclear genome of S. indicum) rather than chromosomal abnormalities (Prabhakaran et al., 1995). Cross between another oil producing crop, B. juncea var. 'Pusa Bold' with its wild species, Diplotaxissii folia followed by repeated backcrosses with $B$. juncea lead to CMS plants having no effect on female fertility however, shrivelled anthers were observed, which failed to dehisce (Rao et al., 1994). Intergeneric hybridization between Festuca pratensis (female parent) and Lolium perenne induced male sterility (cytoplasm/genetic) (Connolly and WrightTurner, 1984). Similarly, cross between Sorghum $\times$ Saccharum showed complete pollen sterility. They mentioned presence of fragmented chromatin material in the anther sac due to abnormalities that occurred during meiosis, degradation of chromatin content in uninucleate cells (Sobhakumari and Nair, 2013).

Based on the amount of genetic material contributed by the two parents involved in the somatic hybridization process recombination of genetic material of the two mitochondria can be used for the development of CMS either by symmetric or asymmetric fusion of protoplast (Garcia et al., 2019). Very recently 
Chen et al., (2020) developed CMS line in a cash crop, tobacco (Nta(gla)S) by asymmetric somatic hybridization between protoplasts of K326 and $N$. glauca followed by backcrossing with K326. These lines were represented by short filaments and shrivelled stamens. Similarly, a novel CMS with carpelloid stamens was induced by protoplast fusion of Chinese Woad and Brassica napus (Kang et al., 2017).

\section{Chemical hybridizing agents (CHAs)}

Though different male sterility systems (GMS, CMS and CGMS) are available, still researchers felt the need for chemical induced male sterility in order to overcome the tedious process of emasculation, which involves tremendous manpower and money demanding for hybrid seed production. Chemical based induction does not involve identification, maintenance of male sterile and restorer lines. They bypass the issues like identification and restoration of male sterile line associated with GMS (McRae, 1985) and is alternative method to generate male sterility in plants. They act as gametocide and target the male gamete by creating abnormalities, thus effecting development of pollen, its viability and its dehiscence (Cross and Ladyman, 1991) without affecting the female fertility.

The mode of action involves disruption of meiosis, interruption of anther development, degeneration of microspores, formation of thin walled exine, non-viable and irregular microspores development. They decrease starch deposition and lead to abnormal growth of tapetal layers. They either prevent or delay the process of dehiscence of normal anthers with viable pollen or inhibit viable pollen germination on stigma or elongation of pollen tube to egg for fertilization, thus leading to induction of sterility (Sharma and Sharma, 2005).
Effect of different gametocides on pollen germination and sterility percentage has been reported in different crops. Induction of male sterility was reported by Moore (1950) in Zea mays L. with maleic hydrazide $(\mathrm{MH})$. Foliar application of 50, 200, $800 \mu \mathrm{g} / \mathrm{ml} \mathrm{MH}$ affected the pollen germination percentage of Phaseolus mungo, P. aureus, Cyamopsistetra gonolob, respectively (Salgare, 2004). Induction of male sterility by ethyl 4fluorooxanilate $\left(\mathrm{E}_{4} \mathrm{FO}\right)$ has been reported as highest pollen and spikelet sterility on application of $1500 \mathrm{ppm}$ when applied at stamen-pistil primordia stage or at a stage between pollen mother cell formation and meiosis (Jahuar et al., 1999) and at a rate of $1.5 \mathrm{mg} / \mathrm{l}$ (Ali et al., 1999) in rice. In wheat $99.7 \%$ sterility was reported without any chemical residues in the plants (Chakraborty and Devakumar, 2006). About 96-99\% male sterility was reported in tef by $\mathrm{E}_{4} \mathrm{FO} @ 1-1.5$ $\mathrm{mg} / \mathrm{l}$ without affecting female fertility (Ghebrehiwot et al., 2015). Application of either $2 \mathrm{mg} / \mathrm{l} \mathrm{E}_{4} \mathrm{FO}$ or $3 \mathrm{ml} / \mathrm{l}$ ethrel was found effective in inducing male sterility in sorghum (Amelework et al., 2016). Other chemicals like ethrel@800 ppm and salicylic acid@ 600 ppm induced high percentage of male sterility in rice (Praba and Thangaraj, 2005). Detergents also have proven effective in induction of sterility of the pollen in crops like mustard, rice (Chauhan and Vandana Singh, 2002), and niger (Gangaprasad et al., 2004) at different concentrations (1 to $6 \%$ ). Complete and long-lasting sterility (91-99\%) was reported by foliar application of surf excel in lentil (Singh, 2017) and 99.87\% pollen sterility in sunflower without effecting the production in sunflower, the treatment led to elongation of the style in floral buds (Tripathi and Singh, 2008). Plant growth regulators (PGR) has also been reported to target the male organ. Application of Gibberellic acid (GA) @ 150 ppm in sunflower resulted in maximum pollen sterility (Garcia Torres, 1979). Duca et al., 
(2014) reported exogenous application of gibberellic acid $\left(\mathrm{GA}_{3}\right)$ induces the expression of CMS specific orfH522 gene in sunflower when applied at apex of inflorescence in the early reproductive stages.

Jinyang et al., (2018) induced male sterility in rapeseed (Brassica napus L.) by Tribenuronmethyl (TBM), herbicide, which inhibits the activity of acetohydroxyacid synthase (AHAS), an enzyme in the first step of the amino acids biosynthesis pathway (branchedchain). Liu et al., (2007), reported high sterility in Brassica napus with novel CHA (EN)@ 0.5- $0.8 \mu \mathrm{g} / \mathrm{mL}$ at uni-nucleic stage, however some effects on female fertility and agronomic traits were also reported. George and Rooney et al., (2018) reported application of TFMSA, trifluoromethanesulfonamide, 2 $\mathrm{mg}$ at 2-6 d (time) before the emergence of flag leaf for inducing male sterile plants in sorghum. Similarly, application of $30 \mathrm{mg}$ TFMSA at $34 \mathrm{~d}$ before the flag leaf emerged also induced complete sterility of the panicle without changes to female fertility and no phytotoxic effects were observed at higher dosage (40 mg). However, genotype dependent response to TFMSA was observed. Clofencet is a pyridazinone, which induced insufficient levels of male sterility in wheat cultivars (Parodi and Gaju, 2009).

Similarly, Benzotriazole, a copper chelating compound that inhibits microspore development (Cross and Schulz, 1997) was found successful in inducing male sterility in a wide range of plants (Shivanna and Sawahney, 1997; Castro et al., 2001). In sunflower complete pollen sterility by Benzotriazole was reported without affecting the seed yield (Tripathi and Singh, 2013). Other mutagenic agents such as acriflavine (1500 ppm), and ethidium bromide (2000 ppm) produced male sterility in sugar beet (Kinoshita et al., 1980, Mikami et al., 1980), CMS lines in Tift $23 \mathrm{DB}_{1}$ (pearl millet) using ethidium bromide (250 and 1,000 ppm) at 5 ${ }^{\circ} \mathrm{C}$ for 40 hours (Burton and Hanna, 1976). SQ-1 is an eco-friendly and approved gametocide that hinders pollen development after meiosis (Cheng et al., 2004). It is generally used as spray for production of male sterile lines at commercial level. SQ-1 has been used to induced male sterility in wheat (Liu et al., 2018), common millet (Cui, 2008), 95-100 \% male sterility by spraying at an optimum dosage in foxtail (Song et al., 2011; Zhang et al., 2017), > $90 \%$ male sterility at $5.0 \mathrm{~kg}$ ha-1 in Maize (Wei et al., 2012).

\section{Induction of male sterility using antibiotics in crops}

Antibiotics are powerful drugs used as antibacterial agents to combat diseases mainly caused by bacteria either destroying or by slowing down the growth of bacteria by targeting the extracellular organelle, which leads to mutation. The endosymbiotic (bacterial origin) nature of mitochondria and chloroplast makes this organelle vulnerable to antibiotics. Both of them have bacterial type ribosome in plants (chloroplasts: $70 \mathrm{~S}$ and mitochondria: 70-80S) that differs with cytoplasm (80S) (Tiller et al., 2012). Some antibiotics (Streptozoocin) are potent mutagen and carcinogenic and leads to point mutations, while other antibiotics have chromosomebreaking properties. Though the mechanism of action of these antibiotics on extracellular organelle is unclear, but it is believed that they induce the formation of toxic reactive oxygen species (ROS) in bacteria and imbalance mito-nuclear protein by effecting mitochondrial translation. Tetracycline at low concentrations reported to induce proteotoxic stress in mitochondria that effects the expression of nuclear genes and hampers the function by modifying fission and fusion process in different organisms including plants (Moullan et al., 2015). 
Fig.1 Cytoplasmic male sterility models: a) Maintenance of CMS line; b) Hybrid seed production using CMS or CGMS system; c) Conversion of breeding line to new male sterile

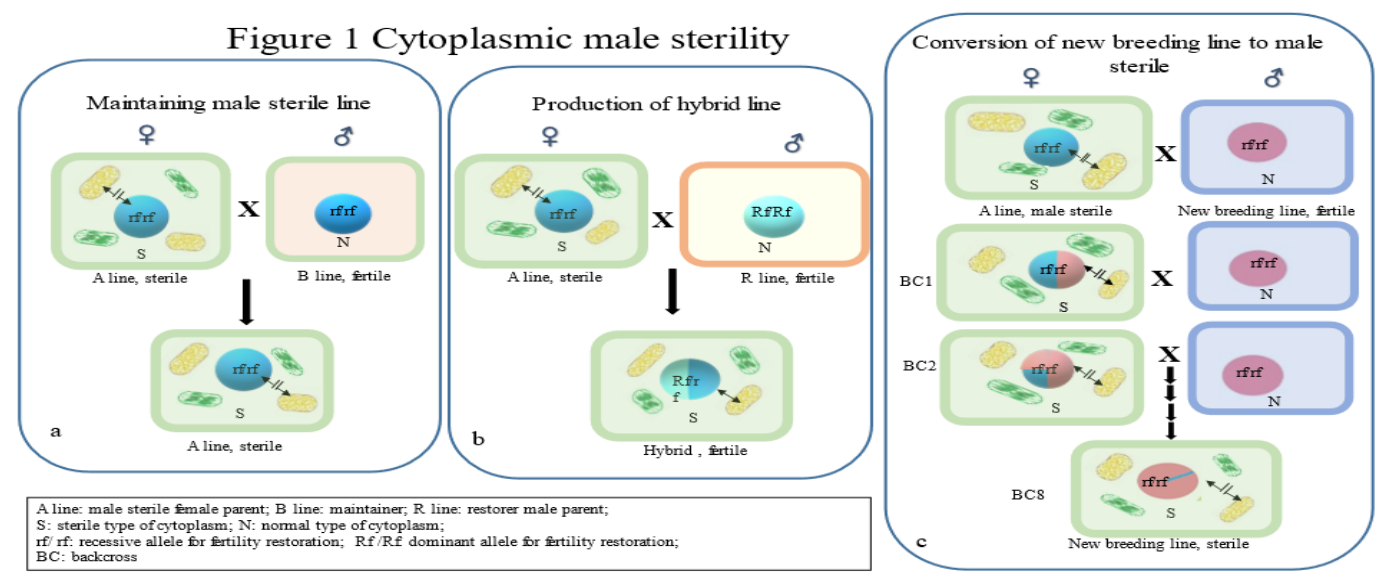

Fig.2 Genetic male sterility, Commercial hybrid seed production

Figure 2 Genetic male sterility

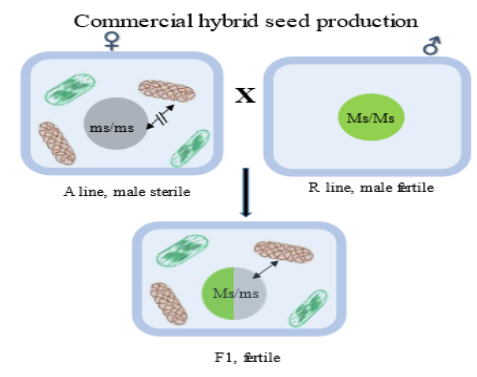

Fig.3 Inheritance of genetic male sterility a) Inheritance of dominant genetic male Sterility, b) Inheritance of recessive genetic male Sterility

Figure 3 Inheritance of genetic male sterility

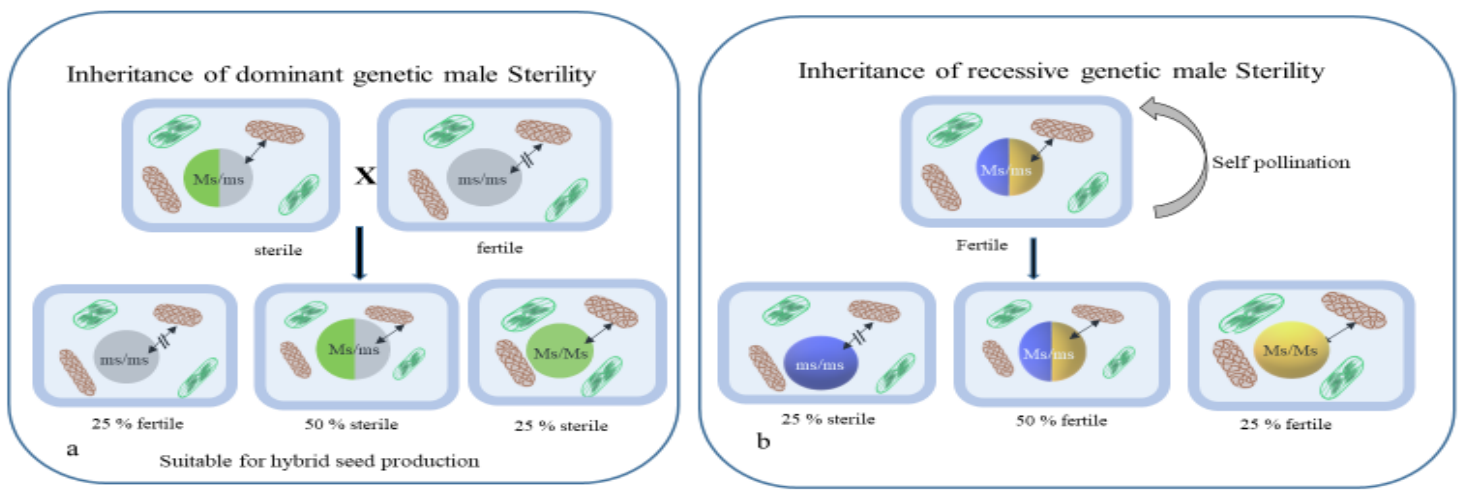


Induction of CMS with chemicals targeting organelle DNA has been explored in some crops. Streptomycin acts as a mutagen by targeting protein translation of nonchromosomal elements (Sager, 1962). These organelles are sensitive to streptomycin and it has been successfully used to induce male sterility in several plant species including rice, sorghum, pearl millet, sugar beet, and sunflower (Elkonin and Tsvetova, 2008). Streptomycin generated mutation of extra chromosomal genes and developed CMS in maize (Petrov et al., 1971), both CMS and GMS in rice at a rate of 250 and $1000 \mathrm{ppm}$ (Sarma and Patnaik, 1932).

Stable CMS mutant were induced with both Mitomycin (50 ppm) and Streptomycin (200 and $500 \mathrm{ppm}$ ) at low temperature for 40 hours in pearl millet (Burton and Hanna, 1982). Both CMS and GMS were induced in cultivated sunflower using Mitomycin $\mathrm{C}$ and Streptomycin (Jan and Rutger, 1988).

In sugar beet $1500 \mathrm{ppm}$ streptomycin induced CMS (Kinoshita et al., 1980). In wheat both stable and complete male-sterile mutants were generated using streptomycin. In-complete male-sterile mutant with low seedset (less than 5\%) was also reported (Zhiyong et al., 1997). Dang et al., (2000) treated oilseed flax with five antibiotics, streptomycin, penicillin, rifampicin, erythromycin and tetracycline @ 0, 500, 1500 and $2000 \mathrm{mg} / \mathrm{l}$ for $24 \mathrm{~h}$ prior sowing and induced male sterile mutants with very low $(0.25 \%-0.8 \%)$ frequency.

We initiated seed treatment of Indian foxtail millet with different doses of streptomycin solution at two different time intervals (24 and $48 \mathrm{~h}$ ) by seed soaking method for induction of heritable male sterility. It resulted in partial sterile inflorescence with sterile pollen grain, however more efforts need to be made in this endeavour.

\section{Transgenic approach}

CMS system suffers with disease susceptibility, poor genetic diversity, and unstable restoration, which can be overcome by GMS system, however, generating malesterile female lines on large-scale by selfpollination is a challenging task. Development of frontier tools and technologies involving rapid methods to identify a MS gene, its isolation, transformation and its introgression into a desired genotype by genetic engineering method for development of a new male sterility systems in plants (Wu et al., 2016, Zhang et al., 2018) has been possible. Male sterility/ restoration system was reported in Brassica juncea using barstar gene for heterosis breeding (Jagannath et al., 2002). Recently, Liu and Yang (2020) transformed $B$. nivea atp9 RNAi vectors into tobacco plants and reported $50 \%$ pollens sterile, thus utilization of atp 9 gene for developing male sterile lines in plants. Similarly, sunflower CMS associated orfH522 gene was transformed into tobacco plants and generated transgenic male sterile lines (Nizampatnam et al., 2009). Whereas, wheat mitochondrial atp9 was transformed to develop transgenic tobacco male sterile lines (Hernould et al., 1993). Roque et al., (2019) reported development of transgenic male sterile using pea anther specific promoter PsEND1 fused with ribonuclease gene in both model and crop plants by aborting anthers in the early stages of development.

Very recently, a new technology CRISPR/Cas9 system has emerged as an effective tool for genome editing (sitespecific) that generates sufficient amounts of mutation and is simple to operate. This, technique has been widely used to develop male sterile lines in different crops. A novel male-sterile line was developed by targeting stamen-specific gene SISTR1 by CRISPR- 
Cas9 and developed a transgenic maintainer by transforming male-sterile plants with a fertility-restoration gene linked to a seedlingcolour gene in tomato ( $\mathrm{Du}$ et al., 2020). Artificially synthesized $\operatorname{Cas} 9$ gene with biased codons targeted MS 8 gene (Chen et al., 2018), and MS26 gene (Djukanovic et al., 2013) in maize to develop male sterile lines. The technology was used to mutate ZmTMS5 gene in maize and generated tms 5 male sterile thermosensitive mutants ( $\mathrm{Li}$ et al., 2017), similarly, TMS5gene was targeted in rice to generate new thermo-sensitive genic male sterile (Barman et al., 2019).

\section{Mitochondria a powerful organelle for male sterility}

Mitochondria and chloroplast are the extracellular organelles endowed with their own genome, and are maternally inherited. Experiments with protoplast fusion showed that CMS phenotype is not associated with chloroplasts. Significant differences on comparison of mtDNA from fertile and CMS plants were reported (Belliard et al., 1979). The trait CMS is associated with morphological and functional damage of mitochondrial and was supported by somatic hybridization and other genetic approaches in tobacco (Belliard et al., 1978). Linkage between CMS and the mitochondrial was strongly supported by reversion of CMS phenotype (Hanson et al., 1989). Mitochondria are the most active organelle that has a tendency to undergo repeated fusion and fission (Tilokani et al., 2018). They are the power house for energy generation and plays crucial role in respiratory energy production via tricarboxylic acid cycle (TCA) and oxidative phosphorylation in eukaryotes. Reduced levels of ATP are associated with increased concentrations of reactive oxygen species (ROS), especially when mitochondria are disfunction, which play a major role in the pollen production (Horn et al., 2014). All the events associated with anther development (microsporogenesis) are tremendous energy demanding, which is mainly fulfilled by the power house of the cell- mitochondria. So, any abnormalities hamper the function of mitochondria, which in turn targets the normal pollen development process leading to cytoplasmic male sterility.

Mechanism lying behind the CMS development is not yet clear, as every male sterile system varies depending upon the mitochondrial gene that is responsible of sterility. However, role of energy deficiency (Heng et al., 2018), reactive oxygen species (ROS) (Liu et al., 2018), programme cell death (PCD) (Qiu et al., 2018) and signals from mitochondria affecting the nuclear pathway (Chakraboraty et al., 2015) are evident. Variation in electron transport of Petunia and toxin-mediated membrane disruption due to toxin in maize plants, bacteria, provide some information about mechanisms for disruption of pollen development (Hanson, 1991). Role of different mitochondrial genes in induction of male sterility in different crops has been reported, Succinate dehydrogenase, $(\mathrm{SDH})$ is a part of mitochondrial complex II, and is involved in TCA cycle and respiratory electron transport chain. Leon et al., (2007) reported pollen abortion and reduced seed set by down-regulating $S D H 1-1$ by RNA interference, which is important for gametophyte development in Arabidopsis. Similarly, Chen et al., (2019) studied role of mitochondria fission in pollen development in Arabidopsis. Dynamic related proteins play major role in mitochondria fission. 3D analysis of single tapetum cell from $d r p 3 a$, $d r p 3 b$, and elm 1 mutant showed change in the volume and shape of tapetal cells, variation in morphology and number of mitochondria in the tapetum during pollen development. These abnormalities in mitochondrial fission led to reductions in pollen development due to 
mitochondrial disruption in the tapetum and pollen (Chen et al., 2019). Tapetum degrades to nourish the pollen grains during their development. Degradation of tapetal cells at right time is prerequisite for normal pollen development. Xie et al., (2020) reported mitochondrial aldehyde dehydrogenase $O s A L D H 2 b$ as a key regulator of tapetum degeneration in rice (Oryza sativa). Mutation in $O s A L D H 2 b$ gene accumulates extra malonaldehyde and early PCD in tapetum, which lead to premature degradation of tapetum and abnormal development of microspores. Recently in wild rice a mitochondrial gene, WA352 was identified that interacts with $\mathrm{COX} 11$, a mitochondrial protein encoded by nucleus. Accumulation of WA352 protein in the tapetum hinders peroxidase metabolism activity of COX11 and leads to PCD followed by pollen abortion and development of CMS (Luo et al., 2013). Another example comes from cotton, where expression of GhLETM1 gene at higher or lower levels lead to defective stamen development with shortened filaments and indehiscent anthers and abortion of pollen (Zhang et al., 2020). RAFTIN gene in rice and wheat (Wang et al., 2003), OsDEX1, a Ca ${ }^{2+}$ binding protein in rice ( $\mathrm{Yu}$ et al., 2016) also been reported to associate with male sterility.

Palumbo et al., (2020) reported role of two atp6 gene sequences for CMS in Fennel (Foeniculum vulgare) by mitochondrial genome assembly of male sterile and fertile accessions. Similarly, the mechanism of abortion in CMS was studied and reported by transcriptome analysis in CMS tobacco and fertile lines (Liu et al., 2020). Wang et al., (2020) identified orf463a gene as the causal factor associated with CMS in radish by next generation sequencing of CMS and fertile mitochondria genome. Another report is from male sterile somatic hybrids obtained from Brassica juncea and Moricardia arvensis, where mitochondrial orf108, was found co- transcribed with atpl gene and reported possibly orf108 either prevents the atpl translation or it translates into a cytotoxic protein (Ashutosh et al., 2008). Similarly, in $B$. juncea expression assays at protein level in CMS (hua lines) showed association of mitochondrial orf 288 that aborts pollen development by cytotoxicity (Jing et al., 2012). Presence of Orf220 and atp-1 in CMS lines of tuber mustard was reported as the reason for CMS in their study (Ming-Fang et al., 2009). Condensed cytoplasm, irregular exine with abnormal or degraded tapetum in TGMS-Brassica napus was correlated with pollen abortion (Sun et al., 2020). CMS lines obtained by protoplast culture of Nicotiana sylvestris showed deletion of mitochondrial DNA and deletion of gene or regulatory effects of deletions that changes the expression of mitochondrial gene was the reasons for CMS trait (Chetrit et al., 1992).

In conclusion the contribution of male sterility in agriculture is unequivocal. Introduction of CMS is crop species is always interesting and useful. On one hand male sterility can be used in commercial seed production, while it can be used in recombination breeding programs for crop improvement. Enumerating the efforts and success in induction of male sterility is useful in understanding the basic mechanism as well as increasing the productivity of crops.

\section{References}

Ali AJ, Devakumar C, Zaman FU, Siddiq EA (1999). Identification of potent gametocides for selective induction of male sterility in rice. Indian Journal of Genetics 59: 429-436.

Amelework A, Laing M, Shimelis H (2016). Evaluation of effective gametocides for selective induction of male sterility in sorghum. Czech Journal of Genetics and Plant Breeding 52: 163-170.

Ashutosh KP, Dinesh KV, Sharma PC, Prakash S, Bhat SR et al., (2008). A novel orf108 cotranscribed with the atpA gene is associated 
with cytoplasmic male sterility in Brassica juncea carrying Moricandia arvensis cytoplasm. Plant and Cell Physiology 49:284289.

Barman HN, Sheng Z, Fiaz S, Zhong M, Yawen Wu et al., (2019). Generation of a new thermosensitive genic male sterile rice line by targeted mutagenesis of TMS5 gene through CRISPR/Cas9 system. BMC Plant Biology 19: 109. https://doi.org/10.1186/s12870-0191715-0.

Belliard G, Pelletier G, Vedel F, Quetier F (1978). Morphological characteristics and chloroplast DNA distribution in different cytoplasmic parasexual hybrids of Nicotiana tabacum. Molecular and General Genetics 165:231237.

Belliard G, Vedel F, Pelletier G (1979). Mitochondrial recombination in cytoplasmic hybrids of Nicotiana tabacum by protoplast fusion. Nature 281: 401-403. https://doi.org/10.1007/BF00332521.

Bohra A, Jha U, Adhimoolam P, Bisht D, Singh N (2016). Cytoplasmic male sterility (CMS) in hybrid breeding in field crops. Plant Cell Reports 35. 10.1007/s00299-016-1949-3.

Burton GW, Hanna WW (1976). Ethidium Bromide Induced Cytoplasmic Male Sterility in Pearl Millet1. Crop Science 16: 731-732. doi:10.2135/cropsci1976.0011183X00160005 0035x.

Burton GW, Hanna WW (1982). Stable cytoplasmic male-sterile mutants induced in tift $23 \mathrm{db} 1$ pearl millet with mitomycin and streptomycin. Crop Science 22: 651-652. https://doi.org/10.2135/cropsci1982.0011183 X002200030053x

Castro S, Davis LC, Erickson LE (2001). Phytodegradation kinetics of methyl benzotriazole. In: Proceedings of the 2001 Conference on Environmental Research, Kansas State University, Manhattan, USA.

Chakraborty A, Mitra J, Bhattacharyya J, Pradhan S, Sikdar N et al., (2015). Transgenic expression of an unedited mitochondrial $\operatorname{orfB}$ gene product from wild abortive (WA) cytoplasm of rice (Oryza sativa L.) generates male sterility in fertile rice lines. Planta 241(6): 1463-1479. https://doi.org/10.1007/s00425015-2269-5.

Chakraborty K, Devakumar C (2006). Evaluation of chemical compounds for induction of male sterility in wheat (Triticum aestivum L.).
Euphytica 147: 329-335. https://doi.org/10.1007/s10681-005-9025-z

Chauhan SVS, Singh V (2002). Detergent-induced male sterility and bud pollination in Brassica juncea (L.) Czern \& Coss. Current Science 82 (8): $\quad 918-20$. doi: $10.1046 / \mathrm{j} .1439-$ 0523.2003.00880.x.

Chen L, Liu YG (2014). Male sterility and fertility restoration in crops. Annual Review of Plant Biology 65:579-606. doi:10.1146/annurevarplant-050213-040119

Chen PY, Wu CC, Lin CC, Jane WN, Suen DF et al., (2019). 3D Imaging of Tapetal Mitochondria Suggests the Importance of Mitochondrial Fission in Pollen Growth. Plant Physiology 180(2):813-826. doi:10.1104/pp.19.00183.

Chen R, Xu Q, Liu Y, Zhang J, Ren D et al., (2018). Generation of Transgene-free maize male sterile lines using the CRISPR/Cas9 system. Frontier Plant Science 9:1180. doi: 10.3389/fpls.2018.01180.

Chen X, Tong Z, Xiao, B. Li Yong-Ping, Jiao FangChan et al., (2020). Identification and evaluation of tobacco cytoplasmic male sterile line $\mathrm{Nta}$ (gla)S K326 generated from asymmetric protoplast fusion of Nicotiana glauca and $N$. tabacum followed by backcrossing with $N$. tabacum K326. Plant Cell Tissue and Organ Culture 142: 269-283. https://doi.org/10.1007/s11240-020-01855-w.

Cheng C, Lu Y, Zhang G, Zhang Z, Li P et al., (2004). The synthesis of genesis and the research of bioactive. Chinese Journal of Pesticide Science 43: 315-317.

Chetrit P, Rios R, De Paepe R, Vitart V, Gutierres S et al., (1992). Cytoplasmic male sterility is associated with large deletions in the mitochondrial DNA of two Nicotiana sylvestris protoclones. Current Genetics 21: 131-137. https://doi.org/10.1007/BF00318472.

Connolly V, Wright-Turner R (1984). Induction of cytoplasmic male-sterility into ryegrass (Lolium perenne). Theoretical and Applied Genetics, 68(5). doi:10.1007/bf00254817

Cross JW, Schulz PJ (1997). (In) Pollen Biotechnology for Crop Production and Improvement, pp 218-36. Shivanna K R and Sawhney V K (Eds). Cambridge University Press.

Cross JW, Ladyman JAR (1991). Chemical agents that inhibit pollen development: tool for 
research. Sexual Plant Reproduction 4: 235243. https://doi.org/10.1007/BF00227655.

Cui X (2008). Male sterility induced by chemical hybridizing agent SQ-1 in common millet. Acta Agronomica Sinica 34: 106-110.

Dang Z, Zhang J, She X (2000). Induction male sterility in linseed by antibiotics treatment Zhongguo you Liao zuo wu xue bao = Chinese Journal of oil Crop Sciences. 22(1):46-48.

Ding D, Gai J, Cui Z, Jiaxun Qiu (2002). Development of a cytoplasmic-nuclear malesterile line of soybean. Euphytica 124:85-91. https://doi.org/10.1023/A:1015683526982.

Djukanovic V, Smith J, Lowe K, Yang M, Gao H et al., (2013). Male-sterile maize plants produced by targeted mutagenesis of the cytochrome P450-like gene (MS26) using a re-designed I-CreI homing endonuclease. Plant Journal 76: 888-899. doi: 10.1111/tpj.12335

Duca M, Port A, Orozco-Cardenas M, Lovatt C (2008). Gibberellin induced gene expression associated with cytoplasmic male sterility in sunflower. Biotechnology and Biotechnological Equipment 22 (2): 691-698. doi: 10.1080/13102818.2008.10817536.

Dufay M, Touzet P, Maurice S, Cuguen J (2007). Modelling the maintenance of male-fertile cytoplasm in a gynodioecious population. Heredity 99(3): 349-356. https://doi.org/10.1038/sj.hdy.6801009.

Du M, Zhou K, Liu Y, Deng L, Zhang X et al., (2020). A biotechnology-based male sterility system for hybrid seed production in tomato. The Plant Journal 102. doi: 10.1111/tpj.14678.

Elkonin LA, Tsvetova MI (2008). Genetic and cytological analyses of the male sterility mutation induced in a sorghum tissue culture with streptomycin. Russian Journal of Genetics 44: 575-583. https://doi.org/10.1134/S1022795408050104.

Fang YN, Zheng BB, Wang L, Yang W, Wu XM et al., (2016). High throughput sequencing and degradome analysis reveal altered expression of miRNAs and their targets in a male-sterile cybrid pummelo (Citrus grandis). BMC Genomics $\quad 17: \quad 591$ https://doi.org/10.1186/s12864-016-2882-0.

Fujii S, Bond C, Small ID (2011). Selection patterns on restorer-like genes reveal a conflict between nuclear and mitochondrial genomes throughout angiosperm evolution. Proceeding of National Academy of Sciences USA 108: 1723-1728.

https://doi.org/10.1073/pnas.1007667108.

Gangaprasad S, Sreedhar RV, Salimth PM, Ravikumar RL (2004). Induction of male sterility in Niger (Guizotia abyssinica Cass.). 4th International Crop Science Congress, Brisbane.

Garcia Torres L, Dominguez Gimenez J, Fernandez Martinez J (1979). Male sterility and female sterility induced in sunflower with GA3. Anales del Institute Nacional de Investigeiones Agrarias, Production Vegetal 9: 147-169.

Garcia L, Edera A, Marfil C, Sanchez-Puerta M (2019). Male Sterility and Somatic Hybridization in Plant Breeding. Preprints, 2019070330

doi: 10.20944/preprints201907.0330.v1

George LH, William LR (2018). Male sterility induction of sorghum using chemical hybridizing agent TFMSA, trifluoromethane sulfonamide. Canadian Journal of Plant Science 98(5): 1102-1108, https://doi.org/10.1139/cjps-2017-0327.

Ghebrehiwot H, Burgdorf R, Shimelis H, Laing M (2015). The efficacy of four gametocides for induction of pollen sterility in Eragrostis tef (Zucc.) Trotter. 14:774-780. 10.5897/AJB2014.14376.

Hanson MR, Pruitt KD, Nivison HT (1989). Male sterility loci in plant mitochondrial genomes. Oxford Surveys of Plant Molecular and Cell Biology 6:61-85.

Hanson MR (1991). Plant Mitochondrial Mutations and Male Sterility. Annual Review of Genetics 25(1): 461-486.

Hanson MR, Bentolila S (2004). Interactions of Mitochondrial and Nuclear Genes That Affect Male Gametophyte Development. Plant Cell 16: $\quad$ 154-169. https://doi.org/10.1105/tpc.015966.

Hernould M, Suharsono S, Litvak S, Araya A, Mouras A (1993). Male-sterility induction in transgenic tobacco plants with an unedited atp9 mitochondrial gene from wheat. Proceeding of National Academy of Sciences USA 90(6): 2370-2374. doi:10.1073/pnas.90.6.2370.

Heng S, Gao J, Wei C, Chen F, Li X, et al., (2018). Transcript levels of orf 288 are associated with the hau cytoplasmic male sterility system 
and altered nuclear gene expression in Brassica juncea. Journal of Experimental Botany 69(3): 455-466. DOI: 10.1093/jxb/erx443

Horn R, Gupta KJ, Colombo N (2014). Mitochondrion role in molecular basis of cytoplasmic male sterility. Mitochondrion 19 (B):198-205. doi:10.1016/j.mito.2014.04.004.

Jagannath A, Arumugam N, GuptaV, Pradhan A, Burma P, Pental D (2002). Development of transgenic barstar lines and identification of a male sterile (barnase)/restorer (barstar) combination for heterosis breeding in Indian oilseed mustard (Brassica juncea). Current Science 82(1):46-52. https://www.jstor.org/stable/24105926.

Jan CC, Rutger JN (1988). Mitomycin C- and Streptomycin induced male sterility in cultivated sunflower. Crop Breeding Genetics and Cytology 28(5):792-79 https://doi.org/10.2135/cropsci1988.0011183 X002800050014x 5.

Jauhar A A, Devakumar C, Zaman FU, Siddiq EA (1999). Gametocidal potency of ethyl 4 fluorooxanilate in rice. Indian Journal of Genetics 59(3): 267-279.

Jing B, Heng S, Tong D, Bin Yi (2012). A male sterility-associated cytotoxic protein ORF288 in Brassica juncea causes aborted pollen development. Journal of Experiment Botany 63(3):1285-1295. doi:10.1093/jxb/err355.

Jinyang LV, Huang Q, Sun Y, Qu G, Guo Y et al., (2018). Male sterility of an AHAS-mutant induced by Tribenuron-Methyl solution correlated with the decrease of AHAS activity in Brassica napus L. Frontiers in Plant Science 9:1014. https://doi.org/10.3389/fpls.2018.01014.

Jones HA, Davis GN (1944). Inbreeding and heterosis and their relation to the development of new varieties of onions. United States Department of Agriculture Technical Bulletin 874:1-28.

Kalia P, Mangal M, Singh S, Chugh C, Mishra S et al., (2019). Morphological and molecular changes on cytoplasmic male sterility (CMS) introgression in Asiatic carrot (Daucus carota L.). Planta 250: 507-518. https://doi.org/10.1007/s00425-019-03185-4.

Kang L, Li P, Wang A, Ge X, Li Z (2017). A novel cytoplasmic male sterility in Brassica napus (inap CMS) with carpelloid stamens via protoplast fusion with Chinese woad. Front.
Plant Sci. 8:529. doi: 10.3389/fpls.2017.00529.

Kasai K, Kanno T, Endo Y, Wakasa K, Tozawa Y (2004). Guanosine tetra-and pentaphosphate synthase activity in chloroplasts of a higher plant: association with $70 \mathrm{~S}$ ribosomes and inhibition by tetracycline. Nucleic Acids Research 32(19): 5732-41 97. DOI: 10.1093/nar/gkh916.

Kaul MLH (1988). Malvaceae. In: Male Sterility in Higher Plants. Monographs on Theoretical and Applied Genetics, vol 10. Springer, Berlin, Heidelberg. https://doi.org/10.1007/978-3-642-831393_34.

Kinoshita T, Takahashi ME, Mikami T (1982). Cytoplasmic Mutation of Male Sterility Induced by Chemical Mutagens in Sugar Beet. Proceedings of the Japan Academy, series B 58(10): 312-322.

Laughnan JR, Gabay-Laughnan S (1983). Cytoplasmic male sterility in maize. Annual Reviews for Genetics 17:27-48. doi: 10.1146/annurev.ge.17.120183.000331

Leon G, Holuigue L, Jordana X (2007). Mitochondrial complex II is essential for gametophyte development in Arabidopsis. Plant Physiology 143(4):1534-1546. doi:10.1104/pp.106.095158.

Li J, Zhang H, Si X, Tian Y, Chen K, Liu J, Chen H, Gao C (2017). Generation of thermosensitive male-sterile maize by targeted knockout of the ZmTMS5 gene. Journal of Genetics and Genomics 44: 465-468. doi: 10.1016/j.jgg.2017.02.002.

Liu FH, Yang F (2020). Male sterility induction and evolution of cytoplasmic male sterility related atp9 gene from Boehmeria nivea (L.) Gaudich. Industrial Crops and Products, 156, 112861.

Liu Z, Liu Y, Sun Y, Yang A, Li F (2020). Comparative Transcriptome analysis reveals the potential mechanism of abortion in Tobacco sua-Cytoplasmic Male Sterility. International Journal for Molecular Sciences 21(7):2445. doi:10.3390/ijms21072445.

Liu XX, Dong JG, Liu CS, Dong ZS, Yan ZB, Gao XL, Gao CY (2007). Effect and utility of a novel chemical hybridizing agent $\mathrm{EN}$ on Brassica napus. Journal of Northwest A \& F University (Natural Science Edition) 4:81-85.

Liu, H., Zhang, G., Wang, J et al., (2018). Chemical hybridizing agent SQ-1-induced male sterility 
in Triticum aestivum $\mathrm{L}$ a comparative analysis of the anther proteome. BMC Plant Biology 18. 7. https://doi.org/10.1186/s12870-0171225-x.

Longin CF, Mühleisen J, Maurer HP, Zhang H, Gowda M, Reif JC (2012). Hybrid breeding in autogamous cereals. Theoretical and Applied Genetics 125(6):1087-96. doi: 10.1007/s00122-012-1967-7.

Luo D, Xu H, Liu Z, Guo J, Li H et al., (2013). A detrimental mitochondrial-nuclear interaction causes cytoplasmic male sterility in rice. Nat Genet 45, 573-577 (2013). https://doi.org/10.1038/ng.2570.

Mackenzie SA, Pring DR, Bassett MJ, Chase CD (1988). Mitochondrial DNA rearrangement associated with fertility restoration and cytoplasmic reversion to fertility in cytoplasmic male sterile Phaseolus vulgaris L. Proceedings of National Academy of Science, USA 85:2714-2717. https://doi.org/10.1073/pnas.85.8.2714.

McRae DH (1985). Advances in chemical hybridization. Plant Breeding Review 3: 169191. https://doi.org/10.1002/9781118061008.ch3.

Mikami T, Kinoshita T, Takahashi H (1980). Induction of male sterility by acridine dyes and streptomycin in sugarbeet. Proceedings of the Sugar Beet Research Association, No.22 pp.48-54 ref.11.

Ming-Fang Zhang, Li-Ping Chen, Bing-Liang Wang, Jing-Hua Yang, Zhu-Jun Chen et al., (2003). Characterization of atpA and orf220 genes distinctively present in a cytoplasmic malesterile line of tuber mustard. The Journal of Horticultural Science and Biotechnology, 78:6, 837-841, doi:10.1080/14620316.2003.11511706

Moore RH (1950). Several effects of maleic hydrazide on plants. Science 112: 52-53. doi: 10.1126/science.112.2898.52.

Moullan N, Mouchiroud L, Wang X et al., (2015). Tetracyclines disturb mitochondrial function across Eukaryotic models: A call for caution in biomedical research. Cell Reports 10(10):1681-1691. doi:10.1016/j.celrep.2015.02.034.

Nizampatnam NR, Doodhi H, Narasimhan YK, Mulpuri S, Viswanathaswamy DK (2009). Expression of sunflower cytoplasmic male sterility-associated open reading frame, orfH522 induces male sterility in transgenic tobacco plants. Planta 229: 987-1001. https://doi.org/10.1007/s00425-009-0888-4.

Palumbo F, Vitulo N, Vannozzi A, Magon G, Barcaccia G (2020). The Mitochondrial Genome Assembly of Fennel (Foeniculum vulgare) Reveals Two Different atp6 Gene Sequences in Cytoplasmic Male Sterile Accessions. International Journal of Molecular Science 21: 4664. https://doi.org/10.3390/ijms21134664.

Parish RW, Li SF (2010) Death of tapetum: a programme of development altruism. Plant Science 178: 73-89. https://doi.org/10.1016/j.plantsci.2009.11.001

Parodi PC, Gaju MD (2009). Male sterility induced by the chemical hybridizing agent clofencet on wheat, Triticum aestivum and T. turgidum var. durum. Ciencia e investigaciónagraria 36(2):267-276. doi.org/10.4067/S071816202009000200011.

Petrov DF, Fokina ES, Zheleznova NB (1971). Method of producing cytoplasmic male sterility in maize - US Patent 3,594,152Google Patents.

Praba ML, Thangaraj M (2005). Effect of growth regulators and chemicals on pollen sterility in TGMS lines of rice. Plant Growth Regulators 46: 117-124. https://doi.org/10.1007/s10725005-7362-5.

Prabakaran AJ, Rangasamy SS, Ramalingam RS (1995). Identification of cytoplasm-induced male sterility in sesame through wide hybridization. Current Science 68(10): 10441047. https://www.jstor.org/stable/24097097.

Qiu Y, Liao L, Jin X, Mao D, Liu R (2018). Analysis of the meiotic transcriptome reveals the genes related to the regulation of pollen abortion in cytoplasmic male-sterile pepper (Capsicum annuum L). Gene 641: 8-17. https://doi.org/10.1016/j.gene.2017.10.022.

Rao GU, Batra-Sarup V, Prakash S, Shivanna KR (1994). Development of a new cytoplasmic male-sterility system in Brassica juncea through wide hybridization. Plant Breeding 112(2):171-174. https://doi.org/10.1111/j.14390523.1994.tb00666.x.

Roque EM, Gómez-Mena C, Hamza R, Beltrán JP, Cañas LA (2019). Engineered Male Sterility by Early Anther Ablation Using the Pea Anther-Specific Promoter PsEND1. Front. Plant Sciences 10: 819. https://doi.org/10.3389/fpls.2019.00819. 
Sager R (1962). Streptomycin as a mutagen for nonchromosomal genes. Proceedings of National Academic Sciences, USA 45: 20182026. doi: 10.1073/pnas.48.12.2018

Salgare SA (2004). Evaluation of $\mathrm{MH}$ as male gametocide and a new method of plant breeding - a critical review. Trends in Biotechnology 9(2): 263-267.

Sarma NP, Patnaik A (1982). Streptomycin Induced Nuclear and Cytoplasm Chloroplast Mutations in Rice. Indian Journal of Experimental Biology 20: 177-178.

Sharma Y, Sharma SN (2005). Chemical Hybridizing Agents (CHA) - A tool for hybrid seed production - A Review. Agricultural Reviews 26 (2): 114 - 123.

Shi MS, Deng JY (1980). The discovery, determination and utilization of the Hubei photosensitive genic male-sterile rice (Oryza sativa L. subsp. japonica). Acta Genetic Sinica 13: 107-112.

Shivanna KR, Sawahney VK (1997). Pollen biotechnology for crop improvement, Cambridge Univ Press, London, UK.

Singh SP, Singh SP, Pandey T, Singh RR, Sawant SV (2015). A novel male sterility-fertility restoration system in plants for hybrid seed production. Scientific Reports 5: 11274.

Singh Netrapal (2017). Induction of male sterility in lentil. International Journal of Botany Studies 2 (6): 205-2082.

Song Y, Wang L, Zhang G, Sheng Y, Li Y et al., (2011). Male sterility induced by chemical hybridizing agent SQ-1 in Setaria italica Beauv. Acta Agronomica Sinica 37: 16951700.

Sobhakumari VP, Nair NV (2013). The Cytological Mechanism of Male Sterility in Intergeneric Hybrids of Sorghum $\times$ Saccharum. Cytologia 79(1): 79-83.

Sun H, Zhao L, Huang M (1997). Cytoplasmic-nuclear male sterile soybean line from interspecific crosses between G. max and G. soja. In B. Napompeth [ed.], Soybean feeds the world, 1994 Proceedings World Soybean Research Conference V, Kasetsart University Press, Bangkok, Thailand, pp 99102.

Sun Y, Zhang D, Wang Z, Guo Y, Sun X et al., (2020). Cytological observation of anther structure and genetic investigation of a thermo-sensitive genic male sterile line 373S in Brassica napus L. BMC Plant Biology
20:8. https://doi.org/10.1186/s12870-0192220-1.

Tiller N, Weingartner M, Thiele W, Maximova E et al., (2012). The plastid-specific ribosomal proteins of Arabidopsis thaliana can be divided into non-essential proteins and genuine ribosomal proteins. Plant Journal 69: 302-16. doi: 10.1111/j.1365313X.2011.04791.x.

Tilokani L, Nagashima S, Paupe V, Prudent J (2018). Mitochondrial dynamics: overview of molecular mechanisms. Essays in Biochemistry $62 \quad$ (3): $\quad 341-360$. doi:10.1042/EBC20170104.

Tripathi SM, Singh K (2013) Hybrid Seed Production in Helianthus annuus L. through Male Sterility Induced by Benzotriazole. Scientific Reports 2:645 doi:10.4172/scientificreports.645.

Tripathi SM, Singh KP (2008). Hybrid seed production in detergent induced male sterile Helianthus annuus L. Helia 31 (49): 103-112. doi: 10.2298/HEL0849103T.

Vinod KK (2005). Cytoplasmic genetic male sterility in plants-A molecular perspective. In: proceedings of training program in "Advances and accomplishments in heterosis breeding", Tamil Nadu Agriculture University, Coimbatore, India, pp: 147-162.

Virmani SS, Ilyas-Ahmed M (2001). Environmentsensitive genic male sterility (EGMS) in crops. Advances in Agronomy 72: 139-195. doi: 10.1016/S0065-2113(01)72013-5.

Wang A, Xia Q, Xie W, Datla R, Selvaraj G (2003). The classical Ubisch bodies carry a sporophytically produced structural protein (RAFTIN) that is essential for pollen development. Proceedings of National Academic Sciences, USA 100: 14487-14492. doi: 10.1016/S0065-2113(01)72013-5.

Wang Y, Wang Q, Hao W, Li J, Qi M, Zhang L (2020). Mitochondrial genome sequencing reveals orf $463 a$ may induce male sterility in NWB cytoplasm of radish. Genes 11: 74. doi: 10.3390/genes11010074.

Wei Fang, Hu Jie, Zhang Xu, Cheng L.-M, Du Juan et al., (2012). Male sterility induced by chemical SQ-1, as an effective male specific gametocide in maize (Zea mays). Maydica 57(3): 244-248.

Wilson ZA, Zhang DB (2009). From Arabidopsis to rice: Pathways in pollen development. Journal of Experimental Biology 60(5):1479-92. 
Doi:10.1093/jxb/erp095.

Wu Y, Fox TW, Trimnell MR, Wang L, Xu RJ et al., (2016). Development of a novel recessive genetic male sterility system for hybrid seed production in maize and other crosspollinating crops. Plant Biotechnology Journal 14: 1046-1054. doi: 10.1111/pbi.12477.

Xie X, Zhang Z, Zhao Z, Xie Y, Li H et al., (2020) The mitochondrial aldehyde dehydrogenase OsALDH2b negatively regulates tapetum degeneration in rice. Journal of Experimental Botany 71(9): 2551-2560. doi: 10.1093/jxb/eraa045.

Yang RC, NY Wang (1989). 5460S indicia photosensitive genic male sterile rice. International Rice Research Newsletters 13: 6-7.

Yu J, Meng Z, Liang W, Behera S, Kudla J, Tucker MR et al., (2016). A rice ca2+ binding protein is required for tapetum function and pollen formation. Plant Physiology 172(3):17721786.

doi: https://doi.org/10.1104/pp.16.01261.

Zhang D, Wu S, An X, Xie K, Dong Z, Zhou Y, Xu $\mathrm{L}$ et al., (2018). Construction of a multicontrol sterility system for a maize malesterile line and hybrid seed production based on the $Z m M s 7$ gene encoding a PHD-finger transcription factor. Plant Biotechnology Journal 16: 459-471. doi: 10.1111/pbi.12786. Zhang H, Guo P, Wang Y, Yuan X, Dong S et al.,
(2017). Assessment of male sterility and antioxidant enzyme activities induced by the chemical hybridization agent SQ-1 in Foxtail Millet (Setaria italica). Emirates Journal of Food and Agriculture 29(3): 212-221. doi: https://doi.org/10.9755/ejfa.2016-10-1530.

Zhang L, Zhang Y, Fan Y, Guo H, Guo H. et al., (2020). Ectopic expressions of the GhLETM1 gene reveal sensitive dose effects on precise stamen development and male fertility in cotton. Genes. 11: 772. doi: 10.3390/genes 11070772 .

Zhang MF, Chen LP, Wang BL, Yang JH, Chen ZJ, Hirata Y (2003). Characterization of atpA and orf220 genes distinctively present in a cytoplasmic male-sterile line of tuber mustard. Journal of Horticulture Science and Biotechnology 78(6): 837-841. doi:10.1080/14620316.2003.11511706.

Zhiyong L, Qixin S, Tiecheng H, Lijiang W (1997). Study on antibiotics-induced male sterility in wheat: II. genic male sterility induced by streptomycin. Journal of China Agricultural University.1:3.

Zhou H, Liu Q, Li J, Jiang D, Zhou L et al., (2012). Photoperiod- and thermo-sensitive genic male sterility in rice is caused by a point mutation in a novel noncoding RNA that produces a small RNA. Cell Research 22: 649-660. doi: 10.1038/cr.2012.28.

\section{How to cite this article:}

Kanti Meena and Visarada K.B.R.S. 2021. Induction of Male Sterility: A Boon for Plant Breeding. Int.J.Curr.Microbiol.App.Sci. 10(02): 1084-1101. doi: https://doi.org/10.20546/ijcmas.2021.1002.128 